\title{
Pengelolaan Kegiatan GLS di Sekolah Dasar Selama Pandemi Covid-19
}

\author{
Management of GLS Activities in Primary Schools During The Covid-19
}

\author{
Atikah Mumpuni*1, Rizki Umi Nurbaeti ${ }^{2}$, Agus Purnomo ${ }^{3}$, Diah Sunarsih ${ }^{4}$, Prasetyo Yuli \\ Kurniawan $^{5}$, Konilah $^{6}$, Erni Ernilah ${ }^{7}$, Nur Laelia Sukmawati ${ }^{8}$ \\ 1,2,3,4,6,7,8 Program Studi Pendidikan Guru Sekolah Dasar, Fakultas Keguruan dan Ilmu Pendidikan, \\ Universitas Muhadi Setiabudi, Indonesia \\ ${ }^{5}$ Program Studi Pendidikan Bahasa dan Sastra Indonesia, , Fakultas Keguruan dan Ilmu Pendidikan, \\ Universitas Muhadi Setiabudi, Indonesia \\ e-mail: ${ }^{* 1}$ atikahmumpuni@umus.ac.id, ${ }^{2}$ rizkiuminurbaeti@umus.ac.id, ${ }^{3}$ aguspurnomo@umus.ac.id. \\ 4diahsunarsih@umus.ac.id, ${ }^{5}$ prasetyoyulikurniawan@umus.ac.id, ${ }^{6}$ konilah@gmail.com, \\ ${ }^{7}$ erniernilah@gmail.com, ${ }^{8}$ nurlaeliasukmawati@gmail.com
}

\begin{abstract}
Abstrak
Kegiatan Gerakan Literasi Sekolah (GLS), khususnya di sekolah dasar mengalami banyak hambataan. Terlebih, saat pandemi Covid-19 seperti saat ini, tentu permasalahan terkait kegiatan GLS semakin kompleks. Oleh sebab itu, perlu dilaksanakan kegiatan pengambdian kepada masyarakat dalam bentuk sosialisasi dan pendampingan pengelolaan kegiatan GLS di Sekolah Dasar selama Pandemi Covid-19. Hasil kegiatan pengabdian kepada masyarakat ini adalah pengelolaan kegiatan GLS selama pandemi Covid-19 dapat dilaksanakan, meskipun dijumpai beberapa permasalahan. Beberapa permasalahan tersebut diantaranya terjadinya penumpukan informasi dan kesulitan akses aplikasi. Saran-saran yang dapat dituliskan yaitu perlu adanya pendampingan orang tua selama kegiatan belajar dari rumah, termasuk pelaksanaan kegiatan GLS. Perlu adanya keberlanjutan kegiatan GLS selama pandemi Covid19, sehingga dapat mengembangkan budi pekerti siswa.
\end{abstract}

Kata kunci: GLS; Sekolah Dasar; Pandemi Covid-19

\begin{abstract}
The activities of the School Literacy Movement (GLS), especially in elementary schools, experience many obstacles. Moreover, during the Covid-19 pandemic like today, of course the problems related to GLS activities are getting more complex. Therefore, it is necessary to carry out community service activities in the form of socialization and assistance in managing GLS activities in elementary schools during the Covid-19 Pandemic. The result of this community service activity is that the management of GLS activities during the Covid-19 pandemic can be carried out, even though several problems have been encountered. Some of these problems include the accumulation of information and difficulty in accessing applications. Suggestions that can be written are the need for parental assistance during learning from home activities, including the implementation of GLS activities. There is a need for the continuity of GLS activities during the Covid-19 pandemic, so that students can develop character.
\end{abstract}

Keyword: GLS; Primary school; The Covid-19 pandemic

\section{PENDAHULUAN}

Gerakan literasi awalnya ada untuk memberantas buta aksara dengan kemampuan membaca dan menulis masyarakat. Akan tetapi, seiring dengan perkembangan zaman dan kemajuan teknologi, kemampuan membaca dan menulis saja dirasa tidak cukup. Orang-orang perlu memahami informasi yang diterimanya, sehingga dapat digunakan secara tepat dalam kehidupan seharihari. Oleh sebab itu, cakupan gerakan literasi menjadi lebih luas, tidak hanya membaca dan menulis, tetapi juga memahami serta menganalisis informasi.

Literasi dapat dilakukan untuk dapat menumbuhkan pengaruh yang positif apabila dilakukan secara berkelanjutan. Konsep literasi pada dasarnya berkembang secara berkelanjutan, sepanjang kehidupan anak (Buvaneswari \& Padakannaya, 2017). Oleh sebab itu, literasi dicanangkan oleh pemerintah dalam suatu Gerakan Literasi Sekolah (GLS) sebagai

Submitted: Januari 2021, Accepted: Februari 2021, Published: Februari 2021

ISSN 2746-6345 (media online) 
upaya berkelanjutan untuk menumbuhkan pengaruh yang baik dalam diri peserta didik. Kegiatan pembiasaan sikap dan perilaku yang positif di sekolah, diintegrasikan dalam gerakan literasi, yaitu dengan membiasakan peserta didik membaca dan menulis untuk menumbuhkan budi pekerti.

GLS dapat dilaksanakan melalui tahapan pembiasaan, pengembangan, dan pembelajaran. Tahapan GLS meliputi tahap pembiasaan, tahap pengembangan, dan tahap pembelajaran (Faizah, 2016). Kegiatan dalam setiap tahapan gerakan literasi di Sekolah Dasar tersebut dapat dikembangkan sesuai dengan ciri khas sekolah dan daerahnya masing-masing. Pertama, tahap pembiasaan, pada tahap ini seluruh warga sekolah akan dibiasakan untuk melakukan aktivitas membaca. Bahan bacaan yang dipilih sebaiknya bahan bacaan yang dapat dinikmati oleh semua warga sekolah. Bahan bacaan yang menarik dapat dipilih untuk dibaca bersama antara guru dengan peserta didik, sehingga dapat menumbuhkan kebiasaan membaca baik pada peserta didik maupun guru (Baverstock et al., 2019). Tentu saja bahan bacaan tersebut adalah bahan bacaan yang memuat nilai-nilai karakter.

Kedua, tahap pengembangan, pada tahap ini, taggihan yang diharapkan adalah dapat memahami informasi yang telah diterima. Literasi bukan hanya membantu membaca simbol, tetapi juga memaknai informasi yang diterima, sehingga siswa dapat memperoleh pemahaman (Gellel, 2018). Pemahaman makna dalam tahap pengembangan literasi ini akan mendukung seseorang dalam mengembangkan dirinya. Ketiga, tahap pembelajaran literasi, pada tahap ini literasi mulai dimasukkan dalam kegiatan pembelajaran. Pembelajaran literasi merupakan hal yang mendasari seseorang untuk terus belajar seumur hidup. Pembelajaran literasi merupakan bagian dari kerangka belajar seumur hidup (McKay, 2018). Melalui pembelajaran literasi seseorang akan membaca informasi, memahami, dan mengembangkannya secara berkelanjutan dalam kehidupannya.

Selama pandemi Covid-19, pelaksanaan kegiatan GLS tentu tidak dapat dikatakan optimal, begitu pula kegiatan GLS terjadi di SDN Tiwulandu 03. Kegiatan belajar dari rumah yang dilakukan selama pandemi Covid-19, tentu membuat setiap tahapan GLS menjadi terhambat. Pada tahap pembiasaan misalnya, ketersediaan bahan bacaan dalam bentuk cetak yang tersedia di sekolah, tentu tidak dapat dimanfaatkan oleh siswa selama kegiatan belajar dari rumah. Begitu pula pada tahap pengembangan dan pembelajaran pada kegiatan GLS yang juga harus dilakukan dari rumah, sehingga guru tidak dapat melakukan pengawasan secara langsung.

Pelaksanaan GLS selama pandemi Covid-19 tentu memerlukan kerja sama yang baik dengan orang tua. Dukungan kolaboratif dalam kegiatan GLS dari berbagai elemen yang diwujudkan melalui pembiasaan, pengembangan, dan pembelajaran membaca peserta didik secara terorganisir sangat diperlukan demi keberhasilan pelaksanaan GLS (Abidin et al., 2018). Dukungan dari berbagai elemen tersebut dapat mengoptimalkan dan meminimalisir hambatanhambatan pelaksanaan GLS. Dengan demikian, GLS dapat berjalan dengan maksimal di sekolah-sekolah, khususnya di Sekolah Dasar.

Lebih lanjut, pengelolaan GLS selama pandemi Covid-19 perlu adanya sosialisasi dan pendampingan. Hal ini dilakukan agar GLS dapat tetap berjalan secara optimal, ditengah pandemi yang sedang mewabah ini. Dengan demikian, budi pekerti siswa yang diharapkan berkembang dari kegiatan GLS akan tetap dapat berkembang sebagaimana yang diharapkan.

\section{METODE PELAKSANAAN}

Sasaran kegiatan pengabdian kepada masyarakat ini adalah guru-guru Sekolah Dasar di Desa Tiwulandu, yang berjumlah 20 orang. Kegiatan pengabdian kepada masyarakat dilaksanakan selama tiga bulan, terhitung dari bulan September ssampai dengan Desember 2020. Peran tim pelaksana terbagi atas narasumber dan pendamping kegiatan. Indikator keberhasilan kegiatan pengabdian kepada masyarakat ini adalah terancangnya pola kegiatan GLS yang dapat diterapkan di Sekolah Dasar selama pandem Covid-19. 
Kegiatan pengabdian kepada masyarakat diawali dengan tahap sosialisasi untuk merancang kegiatan GLS serta tahap pendampingan untuk memaksimalkan pelaksanaan GLS sesuai dengan rancangan yang telah dibuat. Pada tahap sosialisasi, pengarahan dilakukan secara langsung oleh akademisi/dosen. Sementara itu, tahap pendampingan dibantu oleh mahasiswa yang sedang melaksanakan Kuliah Kerja Nyata (KKN) di Desa Tiwulandu. Proses pendampingan dilakukan selama proses pembelajaran dari rumah bersama dengan orang tua. Teknik analisis yang digunakan adalah analisis deskriptif. Analisis deskriptif digunakan untuk menguraikan keberhasilan pengelolaan kegiatan GLS selama pandemi Covid-19.

\section{HASIL DAN PEMBAHASAN}

Sosialisasi Pengelolaan Kegiatan GLS di Sekolah Dasar Selama Pandemi Covid-19

Sosialisasi pengelolaan kegiatan GLS di Sekolah Dasar selama pandemic covid-19 dilaksanakan pada bulan September 2020, bertempat di SDN Tiwulandu 03, Desa Tiwulandu, Kecamatan Banjarharjo. Beberapa hal yang disampaikan yaitu terkait dengan 1) tahap gerakan literasi sekolah; 2) pengelolaan kegiatan GLS selama pandemi Covid-19; dan 3) perancangan kegiatan GLS selama pandemi Covid-19.

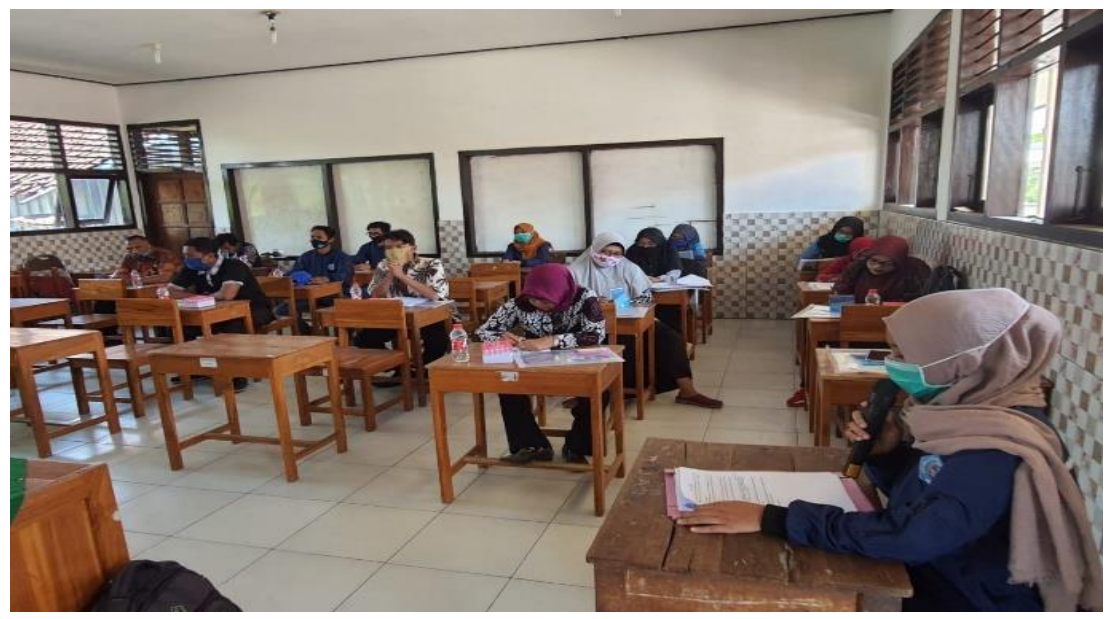

Gambar 1. SOSIALISASI TIM PELAKSANA TERKAIT PENGELOLAAN GLS SELAMA PANDEMI

Tahap GLS masih mengacu pada panduan gerakan literasi di Sekolah Dasar yang terdiri dari tiga tahapan, yaitu tahap pembiasaan, tahap pengembangan, dan tahap pembelajaran (Faizah, 2016). Ketiga tahap GLS tersebut kemudian dikombinasikan dalam kegiatan belajar dari rumah, yang disesuaikan dengan situasi dan kondisi lingkungan siswa.

Pada tahap pembiasaan diisi dengan kegiatan membaca 15 menit sebelum kegiatan pembelajaran untuk menumbuhkan minat baca siswa. Idealnya bahan bacaan yang tersedia adalah bahan bacaaan berbasis digital yang dapat diakses oleh semua siswa dari rumah. Bahan bacaan berbasis digital diartikan sebagai bahan bacaan interaktif yang terintegrasi dengan alat teknologi, seperti komputer atau ponsel sehingga memungkinkan siswa melakukan kegiatan membaca, menulis, berbahasa, dan bertukar informasi secara online (Ellison \& Solomon, 2019). Akan tetapi, bahan bacaan berbasis digital untuk siswa sekolah dasar belum banyak yang tersedia. Terlebih, akses perpustakaan di SDN Tiwulandu 03 belum dapat diakses secara online. Oleh sebab itu, hal ini dapat disiasati dengan peminjaman bahan bacaan kepada siswa secara terjadwal.

Selanjutnya pada tahap pembiasaan dan pembelajaran yang dilakukan dari rumah, tentu guru memerlukan kerjasama yang baik dengan orang tua. Hal ini karena selama proses belajar dari rumah, siswa akan lebih banyak bersama dengan orang tua, sehingga pendampingan 
dan pengawasan ada dibawah kendali orang tua. Proses belajar dari rumah bersama dengan orang tua, tentu banyak hal yang mesti diperhatikan, salah satunya dari pola asuh orang tua (Toharudin \& Rukyat, 2020). Pola asuh yang digunakan orang tua sangat mempengaruhi hasil dari pelaksanaan pendampingan kegiatan GLS selama pandemi Covid-19. Pola asuh yang demokratis, sangat disarankan untuk digunakan. Selain itu, contoh nyata yang diberikan oleh orang tua dan lingkungan yang mendukung akan sangat mempengaruhi keberhasilan pelaksanaan GLS dari rumah.

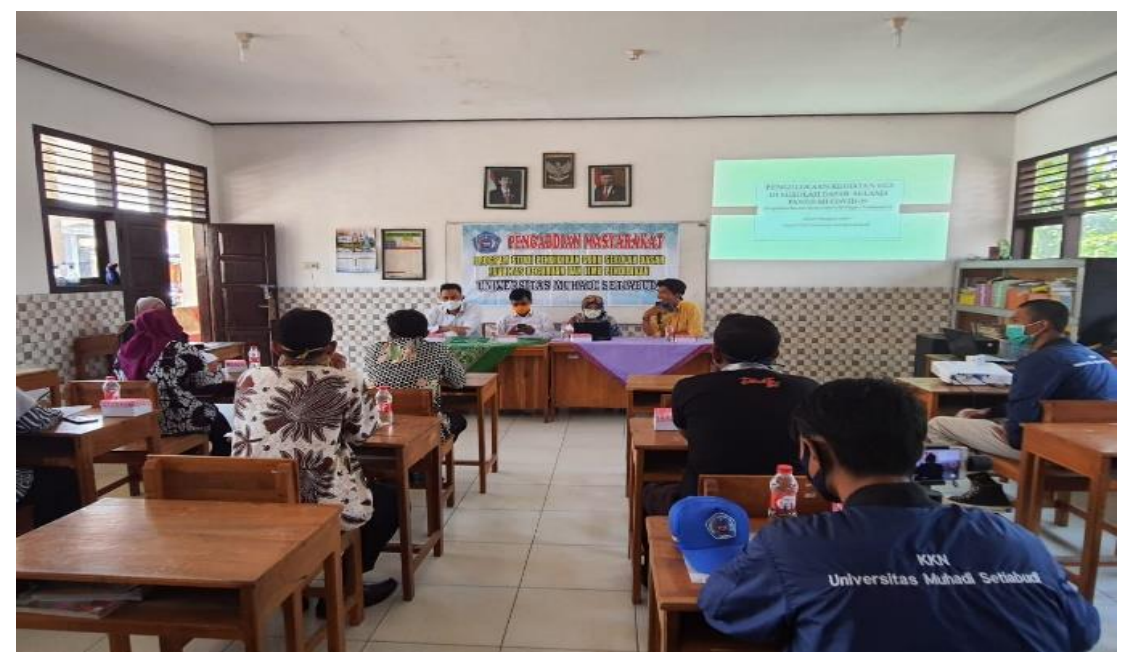

Gambar 2. PERANCANGAN KEGIATAN GLS OLEH GURU-GURU SDN TIWULANDU 03

Peran guru dalam tahap pembiasaan dan pembelajaran dalam kegiatan GLS hanya mengarahkan kegiatan agar GLS dapat terlaksana, meski dari rumah. Beberapa hal yang dipersiapkan guru adalah penyediaan pencatatan secara online agar lebih mempermudah kegiatan GLS. Terakhir tahap perancangan kegiatan GLS selama Covid-19 dilakukan oleh guru sesudah pelaksanaan sosialisasi. Perancangan kegiatan GLS meliputi kegiatan, pembuatan platform, serta penyediaan bahan-bahan pendukung untuk kegiatan GLS selama pandemi Covid-19.

Pendampingan Pengelolaan Kegiatan GLS di Sekolah Dasar Selama Pandemi Covid-19 Pendampingan pengelolaan kegiatan GLS di Sekolah Dasar selama pandemi Covid-19 dilakukan oleh mahasiswa KKN Desa Tiwulandu bersama dosen selama bulan Oktober sampai dengan Desember 2020. Pendampingan kegiatan dilakukan kepada orang tua dan siswa dalam kegiatan GLS dari rumah. Melalui pendampingan ini, diharapkan dapat menjembatani miskonsepsi antara guru dan orang tua dalam tahap pelaksanaan kegiatan GLS dari rumah.

Orang tua dari rumah tentu memiliki peran yang sangat besar dalam keberhasilan pelaksanaan GLS. Keadaaan di lapangan, khususnya di desa Tiwulandu kebanyakan orang tua adalah orang tua pekerja, sehingga kurang dapat mendampingi siswa dalam pelaksanaan tahap kegiatan GLS secara optimal. Terlebih, ketersediaan sarana dan prasarana seperti gaway yang kebanyakan dipegang oleh orang tua. Oleh sebab itu, kerjasama yang baik antara guru dan orang tua sangat diperlukan dalam kegiatan tahap GLS dari rumah. Pendampingan pengelolaan kegiatan GLS di sekolah dasar selama pandemi covid-19 sangat perlu untuk dilakukan karena dijumpai banyaknya permasalahan yang ada. Beberapa permasalahan yang ada seperti penumpukan informasi dan kesulitan orangtua dalam mengakses aplikasi yang digunakan dalam kegiatan GLS dari rumah.

Penumpukan informasi yang terjadi tentu menjadi kendala dalam pelaksanan tahap kegiatan GLS dari rumah. Penumpukan informasi mengakibatkan kegiatan menjadi kurang optimal (Argaheni, 2020). Misalnya, seharusnya sudah tahap pembelajaran, tetapi orang tua melewatkan informasi pada tahap pembiasaan dan pengembangan. Tentu saja hal ini yang 
kemudian mengakibatkan tidak optimalnya pelaksanaan GLS dari rumah jika terjadi penumpukan informasi. Hal inilah yang nantinya menjadi tugas mahasiswa dalam kegiatan pendampingan dengan tujuan agar tidak terjadi penumpukan informasi. Dengan demikian, setiap tahap kegiatan GLS dapat dilaksanakan secara runtut tanpa ada yang terlewat.

Selain adanya penumpukan informasi, beberapa orang tua juga terkendala dalam penggunaan aplikasi yang mendukung tahap kegiatan GLS dari rumah. Beberapa aplikasi yang kerap digunakan oleh guru adalah whatsapp group, google form, dan google classroom (Fuadi et al., 2020). Kendala-kendala tersebut diantaranya kesulitan mengakses aplikasi yang digunnakan, sehingga pendampingan dari mahasiswa sangat perlu dilakukan agar kegiatan GLS dapat dilaksanakan meski dari rumah. Dengan demikian, proses pendampingan dilakukan untuk meminimalisir kendala-kendala teknis pengelolaan kegiatan GLS selama pandemi Covid-19.

\section{KESIMPULAN}

Kesimpulan yang dapat dituliskan dari kegiatan pengabdian kepada masyarakat adalah adanya kegitaan sosialisasi dan pendampingan pengelolaan kegiatan GLS selama pandemi Covid-19 sangat membantu pengoptimalan kegiatan tersebut. Kunci keberhasilan pelaksanaan kegiatan GLS selama pandemi Covid-19 adalah kerjasama dan komunikasi yang baik antara guru dan orang tua. Tanpa adanya kerjasama dan komunikasi yang baik tentu pelaksanaan GLS akan mengalami banyak hambatan.

Setelah dilaksanakannya sosialisasi dan pendampingan pengelolaan kegiatan GLS selama pandemi Covid-19, diharapkan adanya keberlanjutan program. Keberlanjutan program ini sangat diperlukan untuk dapat mendukung perkembangan budi pekerti siswa melalui kegiatan GLS. Dengan demikian, meski dari rumah, guru dan orang tua dapat bersama-sama mengembangkan kepribadian siswa melalui GLS, untuk mempersiapkan siswa bermasyarakat.

\section{UCAPAN TERIMAKASIH}

Ucapan terima kasih disampaikan penulis kepada LP3M Universitas Muhadi Setiabudi yang telah memfasilitasi tim untuk dapat melaksanakan kegiatan pengabdian kepada masyarakat di Desa Tiwulandu.

\section{DAFTAR PUSTAKA}

Abidin, Y., Mulyati, T., \& Yunansah, H. (2018). PEMBELAJARAN LITARASI Strategi Meningkatkan Kemampuan Literasi Matematika, Sains, Membaca, dan Menulis. Bumi Aksara.

Argaheni, N. B. (2020). Sistematik Review: Dampak Perkuliahan Daring Saat Pandemi COVID-19 Terhadap Mahasiswa Indonesia. PLACENTUM: Jurnal Ilmiah Kesehatan Dan Aplikasinya, 8(2), 99. https://jurnal.uns.ac.id/placentum/article/view/43008

Baverstock, A., Steinitz, J., Morris, J., \& Fenwick, C. (2019). What were the processes and outcomes of involving secondary school pupils transitioning from primary to secondary school in pre-arrival shared-reading? A case study. Education 3-13. https://doi.org/10.1080/03004279.2018.1541922

Buvaneswari, B., \& Padakannaya, P. (2017). Development of a home literacy environment questionnaire for Tamil-speaking kindergarten children. Language Testing in Asia, 7(1). https://doi.org/10.1186/s40468-017-0047-y

Ellison, T. L., \& Solomon, M. (2019). Counter-storytelling vs. deficit thinking around African American children and families, digital literacies, race, and the digital divide. Research in the Teaching of English, 53(3), 223-244. 
Faizah, D. U. (2016). Panduan gerakan literasi sekolah di sekolah dasar. In Direktorat Pembinaan Sekolah Dasar Direktorat Jenderal Pendidikan Dasar dan Menengah Kementerian Pendidikan dan Kebudayaan.

Fuadi, T. M., Musriandi, R., \& Suryani, L. (2020). Covid-19 : Penerapan Pembelajaran Daring Di Perguruan Tinggi. Jurnal Dedikasi Pendidikan, 4(2), 193-200.

Gellel, A. M. (2018). Towards a symbol literacy approach in the education of children. International Journal of Children's Spirituality. https://doi.org/10.1080/1364436X.2018.1448761

McKay, V. (2018). Literacy, lifelong learning and sustainable development. Australian Journal of Adult Learning, 58(3), 390-425.

Toharudin, M., \& Rukyat, A. (2020). Model Pendampingan Belajar Pada Anak Keluarga TKW Di SD Negeri Wanacala 02 Brebes. Jurnal Ilmiah KONTEKSTUAL, 2(01), 50-56. https://doi.org/10.46772/kontekstual.v2i01.249 